\section{The New User Environment: The End of Technical Services?}

Editor's Note: "From Our Readers" is an occasional feature highlighting ITAL readers' letters and commentaries on timely issues.

\begin{abstract}
Technical Services: an obsolete term used to describe the largest component of most library staffs in the twentieth century. That component of the staff was entirely devoted to arcane and mysterious processes involved in selecting, acquiring, cataloging, processing, and otherwise making available to library users physical material containing information content pieces (incops). The processes were complicated, expensive, and time-consuming, and generally served to severely limit direct service to users both by producing records that were difficult to understand and interpret, even by other library staff, and by consuming from 75-80 percent of the library's financial and personnel resources. In the twenty-first century, the advent of new forms of publication and new techniques for providing universal records and universal access to information content made the organizational structure obsolete. That change in organizational structure, more than any other single factor, is generally credited as being responsible for the dramatic improvement in the quality of library service that has occurred in the first decade of the twenty-first century.
\end{abstract}

$\mathrm{T}$ here are many who would say that I was the one who wrote this quotation. I didn't, and it is, in fact, more than twenty-five years old! ${ }^{1}$ While I was beginning to research and prepare for this article, I began as most users today start their search for information: I started with Google. Granted, I rarely go beyond the first page of results (as most user surveys indicate), but the paucity of links made me click to the next screen. There, at number 16, was a scanned article. Jackpot! I thought as I started perusing the contents of this resource online, thinking to myself how the future had changed so dramatically since 1984, with the emergence of the Internet and the laptop, all of the new information formats, and the digitization of information. Ahh, the power of full text! After reading through the table of contents, introduction, and the first chapter, I noticed that some of the pages were missing. Mmmm, obviously some very shoddy scanning on the part of Google. But no, I finally realized that only part of this special issue was available on Google. Obviously, I missed the statement at the bottom of the front scan of the book: "This is a preview. The total pages displayed will be limited. Learn more." And thus the issues regarding copyright reared their ugly head.
When discussing the new user environment, there are many demands facing libraries today. In a report by Martha Bates, citing the principle of least effort first attributed to philologist George Zipf and quoted in the Calhoun report to the Library of Congress, she states:

People do not just use information that is easy to find; they even use information that they know to be of poor quality and less reliable-so long as it requires little effort to find-rather than using information they know to be of high quality and reliable, though harder to find ... despite heroic efforts on the part of librarians, students seldom have sufficiently sustained exposure to and practice with library skills to reach the point where they feel real ease with and mastery of library information systems. ${ }^{2}$

According to the final report of Bibliographic Services Task Force of the University of California Libraries, users expect the following:

- one system or search to cover a wide information universe (e.g., Google or Amazon)

- enriched metadata (e.g., ONIX, tables of contents, and cover art)

- full-text availability

- to move easily and seamlessly from a citation about an item to the item itself-discovery alone is not enough

- systems to provide a lot of intelligent assistance

$\checkmark$ correction of obvious spelling errors

- results sorting in order of relevance to their queries

- help in navigating large retrievals through logical subsetting or topical maps or hierarchies

- help in selecting the best source through relevance ranking or added commentary from peers and experts or "others who used this also used that" tools

- customization and personalization services

- authenticated single sign-on

- security and privacy

- communication and collaboration

- multiple formats available: e-books, MPEG, JPEG, RSS and other push technologies, along with traditional, tangible formats

- direct links to e-mail, instant messaging, and sharing

- access to online virtual communities

- access to what the library has to offer without actually having to visit the library ${ }^{3}$

Bradford Lee Eden (eden@library.ucsb.edu) is Associate University Librarian for Technical Services \& Scholarly Communication, University of California, Santa Barbara. 
What is there in this new user environment for those who work in technical services? As indicated in the opening quote, would a dramatic improvement in library services occur if technical services were removed from the organizational structure? Even in 1983, the huge financial investment that libraries made in the organization and description of information, inventory, workflows, and personnel was recognized; today, that investment comes under intense scrutiny as libraries realize that we no longer have a monopoly on information access, and to survive we need to move forward more aggressively into the digital environment than ever before. As Marcum stated in her now-famous article,

- If the commonly available books and journals are accessible online, should we consider the search engines the primary means of access to them?

- Massive digitization radically changes the nature of local libraries. Does it make sense to devote local efforts to the cataloging of unique materials only rather than the regular books and journals?

- We have introduced our cataloging rules and the MARC format to libraries all over the world. How do we make massive changes without creating chaos?

- And finally, a more specific question: Should we proceed with AACR3 in light of a much-changed environment? ${ }^{4}$

There are larger internal issues to consider here as well. The budget situation in libraries requires the application of business models to workflows that have normally not been questioned nor challenged. Karen Calhoun discusses this topic in a number of her contributions to the literature:

When catalog librarians identify what they contribute to their communities with their methods (the cataloging rules, etc.) and with the product they provide (the catalog), they face the danger of "marketing myopia." Marketing myopia is a term used in the business literature to describe a nearsighted view that focuses on the products and services that a firm provides, rather than the needs those products and services are intended to address. $^{5}$

For understanding the implementation issues associated with the leadership strategy, it is important to be clear about what is meant by the "excess capacity" of catalogs. Most catalogers would deny there is excess capacity in today's cataloging departments, and they are correct. Library materials continue to flood into acquisitions and cataloging departments and staff can barely keep up. Yet the key problem of today's online catalog is the effect of declining demand. In healthy businesses, the demand for a product and the capacity to produce it are in balance. Research libraries invest huge sums in the infrastructure that produces their local catalogs, but search engines are students and scholars' favorite place to begin a search. More users bypass catalogs for search engines, but research libraries' investment in catalogs-and in the collections they describe-does not reflect the shift in user demand. ${ }^{6}$

I have discussed this exact problem in recent articles and technical reports as well. ${ }^{7}$ There have to be better, more efficient ways for libraries to organize and describe information not based on the status quo of redundant "localizing" of bibliographic records. A good analogy would be the current price of gas and the looming transportation crisis. For many years, Americans have had the luxury of being able to purchase just about any type of car, truck, SUV, Hummer, etc., that they wanted on the basis of their own preferences, personalities, and incomes, not on the size of the gas tank or on the mileage per gallon. Why not buy a Mercedes over a Kia? But with gas prices now well above the average person's ability to consistently fill their gas tank without mortgaging their future, the market demands that people find alternative solutions in order to survive. This has meant moving away from the status quo of personal choice and selection toward a more economic and sustainable model of informed fuel-efficiency transportation, so much so that public transportation is now inundated with more users than it can handle, and consumers have all but abandoned the truck and SUV markets. Libraries have long worked in the Mercedes arena, providing features such as authority control, subject classification, and redundant localizing of bibliographic records that were essential when libraries held the monopoly on information access but are no longer cost-efficient-nor even sane-strategies in the current information marketplace. Users are not accessing the OPAC anymore; well-known studies indicate that more than 80 percent of information seekers begin their search on a Web search engine. Libraries are investing huge resources in staffing and priorities fiddling with MARC bibliographic records in a time when they are struggling to survive and adapt from a monopoly environment to being just one of many players in the new information marketplace. Budgets are stagnant, staffing is at an all-time low, new information formats continue to appear and require attention, and users are no longer patient nor comfortable working with our clunky OPACs. ${ }^{8}$ Why do libraries continue to support an infrastructure of buying and offering the same books, CDs, DVDs, journals, etc., at every library, when the new information environment offers libraries the opportunity to showcase and present their unique information resources and one-of-a-kind collections to the world? Special collections materials held by every major research and public library in the world can now be digitized, and 
sparse library resources need to be adjusted to compete and offer these unique collections and their services to our users and the world.

The October 2007 issue of Computers in Libraries is devoted solely to articles related to the enhancement, usability, appropriateness, and demise of the library OPAC. Interesting articles include "Fac-Back-OPAC: An Open Source Solution Interface to your Library System," "Dreaming of a Better ILS," "Plug Your Users into Library Resources with OpenSearch Plug-Ins," Delivering What People Need, When and Where They Need It," "The Birth of a New Generation of Library Interfaces," and "Will the ILS Soon Be as Obsolete as the Card Catalog?" An especially interesting quote is given by Cervone, then assistant university librarian for information technology at Northwestern University:

\begin{abstract}
What I'd like to see is for the catalog to go away. To a great degree, it is an anachronism. What we need from the ILS is a solid, business-process back end that would facilitate the functions of the library that are truly unique such as circulation, acquiring materials, and "cataloging" at the item level for what amounts to inventory-control purposes. Most of the other traditional ILS functions could be rolled over into a centralized system, like OCLC, that would be cooperatively shared. The catalog itself should be treated as just another database in the world of resources we have access to. A single interface to those resources that would combine our local print holdings, electronic text (both journal and ebook), as well as multimedia material is what we should be demanding from our vendors. ${ }^{9}$
\end{abstract}

One book that needs to be required reading for all librarians, especially catalogers, is Weinberger's Everything Is Miscellaneous. ${ }^{10} \mathrm{He}$ describes the three orders of order (self organization, metadata, and digital); provides an extensive history of how Western civilization has ordered information, specifically the links to nineteenth-century Victorianism; and the concepts of lumping and splitting. In the end, Weinberger argues that the digital environment allows users to manipulate information into their own organization system, disregarding all previous organizational attempts by supposed experts using outdated and outmoded systems. In the digital disorder of information, an object (leaf) can now be placed on many shelves (branches), figuratively speaking, and this new shape of knowledge brings out four strategic principles:

1. Filter on the way out, not on the way in.

2. Put each leaf on as many branches as possible.

3. Everything is metadata and everything can be a label.

4. Give up control.
It is this last principle that libraries have challenges with. Whether we agree with this principle or not, it has already happened. Arguing about it, ignoring it, or just continuing to do business as usual isn't going to change the fact that information is user-controled and userinitiated in the digital environment.

So, where do we go from here?

\section{The future of technical services (and its staff)}

Far be it from me to try to predict the future of libraries as viable, and more importantly marketable, information organizations in this new environment. One has only to examine the quotations from the first issues of Technical Services Quarterly to see what happens to predictions and opinions. Titles of some of the contributions (from 1983, mind you) are worthy of mention: "Library Automation in the Year 2000," "Musings on the Future of the Catalog," and "Libraries on the Line." There are developments, however, that require reexamination and strategic brainstorming regarding the future of library bibliographic organization and description.

The appearance of WorldCat Local will have a tremendous impact on the disappearance of proprietary vendor OPACs. There will no longer be a need for an integrated library system (ILS); with WorldCat Local, the majority of the world's MARC bibliographic records are available in a Library 2.0 format. The only things missing are some type of inventory and acquisitions module that can be formatted locally and a circulation module. If OCLC could focus their programming efforts on these two services and integrate them into WorldCat Local, library administrators and systems staff would no longer have to deal with proprietary and clunky OPACs (and their huge budgetary lines), but could use the power of Web 2.0 (and hopefully 3.0) tools and services to better position themselves in the new information marketplace.

Another major development is the Google digitization project (and other associated ventures). While there are some concerns about quality and copyright, ${ }^{11}$ as well as issues related to the disappearance of print and the time involved to digitize all print, ${ }^{12}$ no one can deny the gradual and inevitable effect that mass digitization of print resources will have in the new information marketplace. Just the fact that my research explorations for this article brought up digitized portions of the 1983 Technical Services Quarterly articles is an example. More and more, published print information will be available in full-text online. What effect will this have on the physical collection that all libraries maintain, not only in terms of circulation, but also in terms of use of space, preservation, and collection development? No one knows for sure, but if the search strategies and information discovery patterns of our users are any 
indication, then we need to be strategically preparing and developing directions and options.

Automatic metadata generation has been a topic of discussion for a number of years, and Jane Greenberg's work at the University of North Carolina-Chapel Hill is one of the leading examples of research in this area. ${ }^{13}$ While there are still viable concerns about metadata generation without any type of human intervention, semiautomatic and even nonlibrary-facilitated metadata generation has been successful in a number of venues. As libraries grapple with decreased budgets, multiplying formats, fewer staff to do the work, and more retraining and reprofessional development of existing staff, library administrators have to examine all options to maximize personnel as well as budgetary resources. Incorporating new technologies and tools for generating metadata without human intervention into library workflows should be viewed as a viable option. User tagging would be included in this area. Even Intner, a long-time proponent of traditional technical services, has written that generating cataloging data automatically would be of great benefit to the profession, and that more tools and more programming ought to be focused toward this goal. ${ }^{14}$

So, with print workflows being replaced by digital and electronic workflows, how can administrators assist their technical services staff to remain viable in this new information environment? How can technical services staff not only help themselves but their supervisors and administrators to incorporate their unique talents, expertise, education, and experience toward the type of future scenarios indicated above?

\section{Competencies and challenges for technical services staff}

There are some good opinions available for assisting technical services staff with moving into the new environment. Names have power, whether we like to admit it or not, and changing the name from "Technical Services" to something more understandable to our users, let alone our colleagues within the library, is one way to start. Names such as "Collections and Data Management Services" or "Reference Data Services" have been mentioned. ${ }^{15}$ An interesting quote sums up the dilemma:

It's pretty clear that technical services departments have long been the ugly ducklings in the library pond, trumped by a quintet of swans: reference departments (the ones with answers for a grateful public); IT departments (the magicians who keep the computers humming); children's and youth departments (the warm and fuzzy nurturers); other specialty departments (the experts in good reads, music, art, law, business, medicine, government documents, $\mathrm{AV}$, rare books and manuscripts, you-name-it); and administrative groups (the big bosses). Part of the trouble is that the rest of our colleagues don't really know what technical services librarians do. They only know that we do it behind closed doors and talk about it in language no one else understands. If it can't be seen, can't be understood, and can't be discussed, maybe it's all smoke and mirrors, lacking real substance. It's easy to ignore. ${ }^{16}$

Ruschoff mentions competencies for technical services librarians in the new information environment: comfortable working in both print and digital worlds, specialized skills such as foreign languages and subject area expertise, comfortable working in both digital and Web-based technologies (suggesting more computing and technology skills), expertise in digital asset management, and problem-solving analytical skills. ${ }^{17}$ In a recent blog posting summarizing a presentation at the 2008 ALA Annual Conference on this topic, comparisons between catalogers going extinct or retooling are provided. The following is a summary of that post:

\section{Converging trends}

- More catalogers work at the support-staff level than as professional librarians.

- More cataloging records are selected by machines.

- More catalog records are being captured from publisher data or other sources.

- More updating of catalog records is done via batch processes.

- Libraries continue to deemphasize processing of secondary research products in favor of unique primary materials.

What are our choices?

- Behind door number one-the extinction model.

- Behind door number two-the retooling model.

\section{How it's done}

- Extinction

- Keep cranking about how nobody appreciates us.

- Assert over and over that we're already doing everything right-why should we change?

- Adopt a "chicken little" approach to envisioning the future.

- Retooling

- Considers what catalogers already do.

- Look for support.

a Find a new job.

\section{What catalogers do}

- Operate within the boundaries of detailed standards.

- Describe items one-at-a-time.

- Treat items as if they are intended to fit carefully 
within a specific application-the catalog.

- Ignore the rest of the world of information.

\section{What metadata librarians do}

- Think about descriptive data without preconceptions around descriptive level, granularity, or descriptive vocabularies.

- Consider the entirety of the discovery and access issues around a set or collection of materials.

- Consider users and uses beyond an individual service when making design decisions-not necessarily predetermined.

- Leap tall buildings in a single bound.

\section{What new metadata librarians do}

- Be aware of changing user needs.

- Understand the evolving information environment.

- Work collaboratively with technical staff.

- Be familiar with all metadata formats and encoding metadata.

- Seek out tall buildings-otherwise jumping skills will atrophy.

\section{The cataloger skill set}

- AACR2, LC, etc.

\section{The metadata librarian skill set}

- Views data as collections, sets, streams.

- Approaches the task as designing data to "play well with others."

\section{Characteristics of our new world}

- No more ILS

- Bibliographic utilities are unlikely to be the central node for all data.

- Creation of metadata will become more decentralized.

- Nobody knows how this will all shake out, but metadata librarians will be critical in forging solutions. ${ }^{18}$

While the above summary focuses on catalogers and their future, many of the directions also apply to any librarian or support staff member currently working in technical services. In a recent EDUCAUSE Review article, Brantley lists a number of mantras that all libraries need to repeat and keep in mind in this new information environment:

- Libraries must be available everywhere.

- Libraries must be designed to get better through use.

- Libraries must be portable.

- Libraries must know where they are.

- Libraries must tell stories.

- Libraries must help people learn.

- Libraries must be tools of change.

- Libraries must offer paths for exploration.
- Libraries must help forge memory.

- Libraries must speak for people.

- Libraries must study the art of war. ${ }^{19}$

You will have to read the article to find out about that last point. The above mantras illustrate that each of these issues must also be aligned with the work done by technical services departments in support of the rest of the library's services. And there definitely isn't one right way to move forward; each library with its unique blend of services and staff has to define, initiate, and engender dialogue on change and strategic direction, and then actively make decisions with integrity and vigor toward both its users and its staff. As Calhoun indicates, there are a number of challenges to feasibility for next steps in this area, some technically oriented but many based on our own organizational structures and strictures:

- Difficulty achieving consensus on standardized, simplified, more automated workflows.

- Unwillingness or inability to dispense with highly customized acquisitions and cataloging operations.

- Overcoming the "not invented here" mindset preventing ready acceptance of cataloging copy from other libraries or external sources.

- Resistance to simplifying cataloging.

- Inability to find and successfully collaborate with necessary partners (e.g., ILS vendors).

- Difficulty achieving basic levels of system interoperability.

- Slow development and implementation of necessary standards.

- Library-centric decision making; inability to base priorities on how users behave and what they want

- Limited availability of data to support management decisions.

- Inadequate skill set among library staff; unwillingness or inability to retrain.

- Resistance to change from faculty members, deans, or administrators. ${ }^{20}$

\section{Moving forward in the new information world}

In a recent discussion on the Autocat electronic discussion list regarding the client-business paradigm now being impressed on library staff, an especially interesting quote puts the entire debate into perspective:

The irony of this discussion is that our patrons/users/ clients [et al.] expect to be treated as well as business customers. They pay tuition or taxes to most of our institutions and expect to have a return in value. And a very large percentage of them care about the differences between the government services vs. business 
arguments we present. What they know is that when they want something, they want it.

More library powers-that-be now come from the world of business rather than libraries because of the pressure on the bottom line. Business administrators are viewed, even by those in public administration, as being more fiscally able than librarians. I would recommend that we fuss less about titles and semantics and develop ways to show the value of libraries to the public. $^{21}$

Wheeler, in a recent Educause Review article, documents a number of "eras" that colleges and universities have gone through in recent history. ${ }^{22}$ First is the "Era of Publishing," followed by the "Era of Participation" with the appearance of the Internet and its social networking tools. The next era, the "Era of Certitude," is one in which users will want quick, timely answers to questions, along with some thought about the need and context of the question. Wheeler espouses five dimensions that tools of certitude must have: reach, response, results, resources, and rights. He explains these dimensions in regards to various tools and services that libraries can provide through human-human, human-machine, and machine-machine interaction. $^{23}$ Wheeler sees extensive rethinking and reengineering by libraries, campuses, and information technology to assist users to meet their information needs. Are there ways that technical services staff can assist in these efforts?

Although somewhat dated, Calhoun's extensive article on what is needed from catalogers and librarians in the twenty-first century expounds a number of salient points. ${ }^{24}$ In table 1, she illustrates some of the many challenges facing traditional library cataloging, providing her opinion on what the challenges are, why they exist, and some solutions for survivability and adaptability in the new marketplace. ${ }^{25}$ One quote in particular deserves attention:

At the very least, adapting successfully to current demands will require new competencies for librarians, and I have made the case elsewhere that librarians must move beyond basic computer literacy to "IT fluency"-that is, an understanding of the concepts of information technology, especially applying problem solving and critical thinking skills to using information technology. Raising the bar of IT fluency will be even more critical for metadata specialists, as they shift away from a focus on metadata production to approaches based on IT tools and techniques on the one hand, and on consulting and teamwork on the other. As a result of the increasing need for IT fluency among metadata specialists, they may become more closely allied with technical support groups in campus computing centers. The chief challenges for metadata specialists will be getting out of library back rooms, becoming familiar with the larger world of university knowledge communities, and developing primary contacts with the appropriate domain experts and IT specialists. ${ }^{26}$

Getting out of the back room and interacting with users seems to be one of the dominant themes of evolving technical services positions to fit the new information marketplace. Putting Web 2.0 tools and services into the library OPAC has also gained some momentum since the launch of the Endeca-based OPAC at North Carolina State University. As some people have stated, however, putting "lipstick on a pig" doesn't change the fundamental problems and poor usability of something that never worked well in the first place. ${ }^{27}$ In their recent article, Jia Mi and Cathy Weng tried to answer the following questions: Why is the current OPAC ineffective? What can libraries and librarians do to deliver an OPAC that is as good as search engines to better serve our users? ${ }^{28}$ Of course, the authors are biased toward the OPAC and wish to make it better, given that the last sentence in their abstract is, "Revitalizing the OPAC is one of the pressing issues that has to be accomplished." Users' search patterns have already moved away from the OPAC as a discovery tool; why should personnel and resource investment continue to be allocated toward something that users have turned away from? In their recommendations, Mi and Weng indicate that system limitations, not fully exploiting the functionality already made available by ILSs, and the unsuitability of MARC standards to online bibliographic display are the primary factors to the ineffectiveness of library OPACs. Exactly. Debate and discussion on Autocat after the publication of their article again shows the line drawn between conservative opinions (added value, noncommercialization, and overall ideals of the library profession and professional cataloging workflows) and the newer push for open-source models, junking the OPAC, and learning and working with non-MARC metadata standards and tools.

\section{Conclusion}

From an administrative point of view, there are a number of viable options for making technical services as efficient as possible, in its current emanation:

- Conduct a process review of all current workflows, following each type of format from receipt at loading dock to access by user. Revise and redesign workflows for efficiency.

- Eliminate all backlogs, incorporating and standardizing various types of bibliographic organization (from brief records to full records, using established criteria of importance and access).

- As much as possible, contract with vendors to make 
all print materials shelf-ready, establishing and monitoring profiles for quality and accuracy. Establish a rate of error that is amenable to technical services staff; once that error rate is met, review incoming print materials only once or twice a year.

- Assure technical services staff that their skills, experience, and attention to detail are needed in the electronic environment, and provide training and professional development to assist them in scanning and digitizing unique collections, learning non-MARC metadata standards, improving project management, and performing consultation training to interact with faculty and students who work with data sets, metadata, and research planning. Support and actively work for revised job reclassification of library support staff positions.

Most libraries are forced to work with fewer staff, and it is essential that current personnel are valued for their institutional knowledge and skill sets (knowledge management philosophy). Library administrations need to emphasize to their staff that the organization has a vested interest in providing them with the tools and training they need to assist the organization in the new information marketplace. The status quo of technical services operations is no longer viable or cost-effective; all of us must look at ways to regain market share and restructure our organizations to collaborate and consult with users regarding their information and research needs. No longer is it enough to just provide access to information; we must also provide tools and assistance to the user in manipulating that information.

To end, I would like to quote from a few of the articles from that 1983 issue of Technical Services Quarterly I have alluded to throughout this chapter:

Like all prognostications, predictions about cataloging in a fully automated library may bear little resemblance to the ultimate reality. While the future cataloging scenario discussed here may seem reasonable now, it could prove embarrassing to read 10-20 years hence. Still, I would be pleasantly surprised if, by the year 2000, TS operations are not fully integrated, TS staff has not been greatly reduced, there has not been a large-scale jump in TS productivity accompanied by a dramatic decline in TS costs, and if most of us are not cooperating through a national database. ${ }^{29}$

In conclusion, I will revert to my first subject, the uncertain nature of predictions. In addition to the fearless predictions already recorded, I predict that some of these predictions will come true and perhaps even most of them. Some of them will come true, but not in the time anticipated, while others never will. Let us hope that the influences not guessed that will prevent the actualization of some of these predictions will be happy ones, not dire. However they turn out, I predict that in ten years no one will remember or really care what these predictions were. ${ }^{30}$

Technical services as we know them now may well not exist by the end of the century. The aims of technical services will exist for as long as there are libraries. The Technical Services Quarterly may well have changed its name and its coverage long before then, but its concerns will remain real and the work to which many of us devote our lives will remain worthwhile. There can be few things in life that are as worth doing as enabling libraries to fulfill their unique and uniquely important role in culture and civilization. ${ }^{31}$

Twenty-five years have come and gone; some of the predictions in this first issue of Technical Services Quarterly came true, many of them did not. There have been dramatic changes in those twenty-five years, most of which were unforeseen, as they always are. What is a certainty is that libraries can no longer sustain or maintain the status quo in technical services. What also is a certainty is that technical services staff, with their unique skills, talents, abilities, and knowledge in relation to the organization and description of information, are desperately needed in the new information environment. It is the responsibility of both library administrators and technical services staff to work together to evolve and redesign workflows, standards, procedures, and even themselves to survive and succeed into the future.

\section{References}

1. Norman D. Stevens, "Selections from a Dictionary of Libinfosci Terms," in "Beyond '1984': The Future of Technical Services," special issue, Technical Services Quarterly 1, no. 1-2 (Fall/Winter 1983): 260.

2. Marcia J. Bates, "Improving User Access to Library Catalog and Portal Information: Final Report," (paper presented at the Library of Congress Bicentennial Conference on Bibliographic Control for the New Millennium, June 1, 2003): 4, http://www.loc.gov/catdir/bibcontrol/2.3BatesReport6-03 .doc.pdf (accessed Apr. 7, 2009). See also Karen Calhoun, "The Changing Nature of the Catalog and Its Integration with Other Discovery Tools," final report to the Library of Congress, Mar. 17, 2006, 25, http://www.loc.gov/catdir/calhoun-report-final .pdf (accessed Apr. 7, 2009).

3. University of California Libraries Bibliographic Services Task Force, "Rethinking How We Provide Bibliographic Services for the University of California," final report, Dec. 2005, 8, http://libraries.universityofcalifornia.edu/sopag/BSTF/Final. pdf (accessed Apr. 7, 2009).

4. Deanna B. Marcum, "The Future of Cataloging," Library Resources E Technical Services 50, no. 1 (Jan. 2006): 9, http:/ / www loc.gov/library/reports/CatalogingSpeech.pdf (accessed Apr. 
7, 2009).

5. Karen Calhoun, "Being a Librarian: Metadata and Metadata Specialists in the Twenty-First Century," Library hi tech 25, no. 2 (2007), http://www.emeraldinsight.com/Insight/View ContentServlet?Filename=Published $/$ EmeraldFullTextArticle / Articles/2380250202.html (accessed Apr. 7, 2009).

6. Calhoun, "The Changing Nature of the Catalog," 15.

7. Bradford Lee Eden, "Ending the Status Quo," American Libraries 39, no. 3 (Mar. 2008): 38; Eden, introduction to "Information Organization Future for Libraries," Library Technology Reports 44, no. 8 (Nov./Dec. 2007): 5-7.

8. See Karen Schneider's "How OPACs Suck" series on the ALA TechSource blog, http://www.techsource.ala.org/ blog/2006/03/how-opacs-suck-part-1-relevance-rank-or-the -lack-of-it.html,http:/ /www.techsource.ala.org/blog/2006/04/ how-opacs-suck-part-2-the-checklist-of-shame.html, and http:/ / www.techsource.ala.org/blog/2006/05/how-opacs-suck-part3-the-big-picture.html (accessed Apr. 7, 2009).

9. H. Frank Cervone, quoted in Ellen Bahr, "Dreaming of a Better ILS," Computers in Libraries 27, no. 9 (Oct. 2007): 14.

10. David Weinberger, Everything Is Miscellaneous: The Power of the New Digital Disorder (New York: Times, 2007).

11. For a list of these concerns, see Robert Darnton, "The Library in the New Age," The New York Review of Books 55, no. 10 (June 12, 2008), http://www.nybooks.com/articles/21514 (accessed Apr. 7, 2009).

12. See Calhoun, "The Changing Nature of the Catalog," 27.

13. See the Metadata Research Center, "Automatic Metadata Generation Applications (AMeGA)," http://ils.unc.edu/mrc/ amega (accessed, Apr. 7, 2009).

14. Sheila S. Intner, "Generating Cataloging Data Automatically," Technicalities 28, no. 2 (Mar./Apr. 2008): 1, 15-16.

15. Sheila S. Intner, "A Technical Services Makeover," Technicalities 27, no. 5 (Sept./Oct. 2007): 1, 14-15.

16. Ibid, 14 (emphasis added).

17. Carlen Ruschoff, "Competencies for 21st Century Techni- cal Services," Technicalities 27, no. 6 (Nov./Dec. 2007): 1, 14-16.

18. Diane Hillman, "A Has-Been Cataloger Looks at What Cataloging Will Be," online posting, Metadata Blog, July 1, 2008, http:/ / blogs.ala.org/nrmig.php?title=creating_the_future_of_ the_catalog_aamp_\&more $=1 \& \mathrm{c}=1 \& \mathrm{tb}=1 \& \mathrm{pb}=1$ (accessed Apr. 7, 2009).

19. Peter Brantley, "Architectures for Collaboration: Roles and Expectations for Digital Libraries," Educause Review 43, no. 2 (Mar./ Apr. 2008): 31-38.

20. Calhoun, "The Changing Nature of the Catalog," 13.

21. Brian Briscoe, "That Business/Customer Stuff (Was: Letter to AL)," online posting, Autocat, May 30, 2008.

22. Brad Wheeler, "In Search of Certitude," Educause Review 43, no. 3 (May/June 2008): 15-34.

23. Ibid., 22.

24. Karen Calhoun, "Being a Librarian."

25. Ibid.

26. Ibid. (emphasis added).

27. Andrew Pace, quoted in Roy Tennant, "Digitl Libraries: 'Lipstick on a Pig,',' Library Journal, Apr. 15, 2005, http:// www.libraryjournal.com/article/CA516027.html (accessed Apr. 7, 2009).

28. Jia Mi and Cathy Weng, "Revitalizing the Library OPAC: Interface, Searching, and Display Challenges," Information Technology E Libraries 27, no. 1 (Mar. 2008): 5-22.

29. Gregor A. Preston, "How Will Automation Affect Cataloging Staff?" in "Beyond '1984': The Future of Technical Services," special issue, Technical Services Quarterly 1, no. 1-2 (Fall/ Winter 1983): 134.

30. David C. Taylor, "The Library Future: Computers," in "Beyond '1984': The Future of Technical Services," special issue, Technical Services Quarterly 1, no. 1-2 (Fall/Winter 1983): 92-93.

31. Michael Gorman, "Technical Services, 1984-2001 (and before)," in "Beyond '1984': The Future of Technical Services," special issue, Technical Services Quarterly 1, no. 1-2 (Fall/Winter 1983): 71.

\section{Index to Advertisers}

LITA

Neal-Schuman cover 2 , cover 3

cover 4 